\title{
Patient satisfaction with removable partial dentures and related factors - A Pilot study
}

\author{
Mallika S Shetty ${ }^{1}$, Ganesh Shenoy Panchamal ${ }^{2}$, Kamalakanth K Shenoy ${ }^{3}$
}

${ }^{1}$ Reader, Department of Prosthodontics, Yenepoya Dental College, Deralkatte, Mangalore, Karnataka, India.

${ }^{2}$ Professor and Head, Department of Public health dentistry, Yenepoya Dental College, Yenepoya University, Karnataka, India.

${ }^{3}$ Professor and head, Department of Prosthodonics, Yenepoya Dental College, Yenepoya University, Karnataka,I ndia

\section{Corresponding Author:}

Dr. Mallika S Shetty

\section{Address:}

Reader, Department of Prosthodontics, Yenepoya Dental College, Deralkatte, Mangalore, Karnataka, India.

Tel: +919448131550

E-mail:

mallika_msshetty@yahoo.com

Başvuru Tarihi/Received :

12-07-2014

Kabul Tarihi/Accepted:

07-08-2014

\section{ABSTRACT}

Background: Removable partial dentures play a pivotal role in restoring the overall comfort of the patient. Every skilled professional constructs dentures with utmost care, even then some patients will still be dissatisfied with their new dentures. The aim of this study is to know the effectiveness of therapy by evaluating patient satisfaction with function, appearance, retention and stability and comfort of removable prosthesis and to relate the influence of age, gender and level of education with patient satisfaction.

Materials and methods: A cross sectional survey was conducted among the rural population of Mangalore taluk. The study involved completion of a pre-designed proforma. Statistical analysis of the data was done using the chi square test with the $\mathrm{p}$ value of $<0.05$ considered significant.

Results: A total of 582 subjects aged 20 years and above formed the study population. Males were more satisfied with the appearance and comfort of the prosthesis. Females were more satisfied with the functioning of the prosthesis. Satisfaction with the function and appearance of the prosthesis was seen more in subjects of age group $>70$ and least in subjects of age group 2130. Satisfaction with the functioning of the prosthesis was seen more in illiterates and least in graduates.

Conclusion: No matter how skilled a professional is, the acceptance of the prosthesis plays a major role in its success. Besides rehabilitation the professional must also motivate the subjects and create positive attitude towards prosthetic acceptance.

Key words: patient satisfaction, removable prosthesis, retention, appearance 


\section{DOI: $10.16899 /$ ctd.58786}

\section{INTRODUCTION}

Removable partial dentures play a pivotal role in restoring the functions of mastication, esthetics, speech and overall comfort of the patient. Every skilled professional constructs dentures with utmost care and complies with all the accepted criteria. Even then some patients will still be dissatisfied with their new dentures. Several studies have been conducted to find out the factors which influence patient's satisfaction, and have found that satisfaction with the dental prosthesis has multifactorial dimensions involving technical and patient related variables. Comfort, masticatory ability, aesthetics and retention seem to be the most important factors for satisfaction with the prosthesis (1).

Access to dental care is limited in a rural population and there is a paucity of data on removable partial dentures and their acceptability in a rural population. Therefore, the aim of this study was to know the effectiveness of therapy by evaluating patient satisfaction with function, appearance, retention and stability and comfort of removable prosthesis in a rural population. We also attempted to relate the influence of age, gender and level of education with patient satisfaction.

\section{MATERIALS AND METHODS}

A cross sectional survey was conducted among the rural population of Mangalore Taluk between August 2013 and December 2013.

Out of 49 gram panchayats in Mangalore taluk 7 were randomly selected. In the selected gram panchayats with a house-to-house approach subjects who fulfilled the inclusion criteria were interviewed by the investigator. Subjects of 20 years or more in age who had removable partial dentures were included in the study. The subjects who met the requirements were informed of the nature of the Investigation and their consent was obtained. Subjects who were not co-operative and who did not give consent were excluded from the study. Confidentiality was assured to participants and all recording forms were numbered, but not named. Approval for the study was obtained from the Yenepoya University ethics committee. The study involved completion of a predesigned proforma.

It was structured in 2 parts which recorded the

1. Sociodemographic factors (age, gender, education)

2.The satisfaction level of subjects with their dental prosthesis in terms of appearance, retention and stability, function (ability to speak , chew ,consume water ,blow, and swallow), comfort (pain ,ulcer, food lodgement under the prosthesis, chewing, laughing, swallowing, yawning, inserting or removing the denture).Each of these items was rated as satisfactory or dissatisfactory.

Statistical analysis of the data was done using the SPSS version 17.0. Chi square test was used for data analysis with the $\mathrm{p}$ value of $<0.05$ considered significant.

\section{RESULT}

A total of 582 subjects [255 males (43.6\%) and 327 females (56.4\%)] aged 20 years and above formed the study population.

The distribution of subjects according to their age group and gender is given in Table 1 .

Table 1: Distribution of subjects according to their age group and gender

\begin{tabular}{|c|c|c|c|}
\hline \multicolumn{2}{|c|}{ AGE GROUP } & \multicolumn{2}{|c|}{ ENDER } \\
\hline & MALE & FEMALE & TOTAL \\
\hline$<20$ & $13(30.2 \%)$ & $30(69.8 \%)$ & $43(100.0 \%)$ \\
\hline $\begin{array}{l}\mathbf{2 1 - 3 0} \\
156(100\end{array}$ & $54(34.1 \%)$ & $102(65.9 \%)$ & \\
\hline $\begin{array}{l}\mathbf{3 1 - 4 0} \\
127(100\end{array}$ & $40(31.5 \%)$ & $87(68.5 \%)$ & \\
\hline $\begin{array}{l}\mathbf{4 1 - 5 0} \\
102(100\end{array}$ & $56(53.9 \%)$ & $46(46.1 \%)$ & \\
\hline $51-60$ & $53(58.9 \%)$ & $37(41.1 \%)$ & $90(100.0 \%)$ \\
\hline $61-70$ & $31(59.6 \%)$ & $21(40.4 \%)$ & $52(100.0 \%)$ \\
\hline$>70$ & $8(66.7 \%)$ & $4(33.3 \%)$ & $12(100.0 \%)$ \\
\hline TOTAL & $255(43.6 \%)$ & $327(56.4 \%)$ & $582(100.0 \%)$ \\
\hline
\end{tabular}


According to the educational background $3.9 \%$ were illiterate, $48.0 \%$ attended primary school, $42.7 \%$ attended high school and $5.4 \%$ were graduates.

The distribution of subjects according to Patients satisfaction and gender is given in Table 2. Males were more satisfied than females with the appearance and comfort of the prosthesis. Females were more satisfied with the function of the prosthesis than the males. Only $1 \%$ of the total population were satisfied with the retention and stability. Patient's satisfaction was found to be very highly significantly related to gender.

The distribution of subjects according to Patients satisfaction and Age group is given in Table 3. Satisfaction with the function and appearance of the prosthesis was seen more in subjects of age group $>70$ and least in subjects of age group 21-30. Patients satisfaction and age group was found to be very highly significant.
Table 2. Distribution according to Patients satisfaction and gender

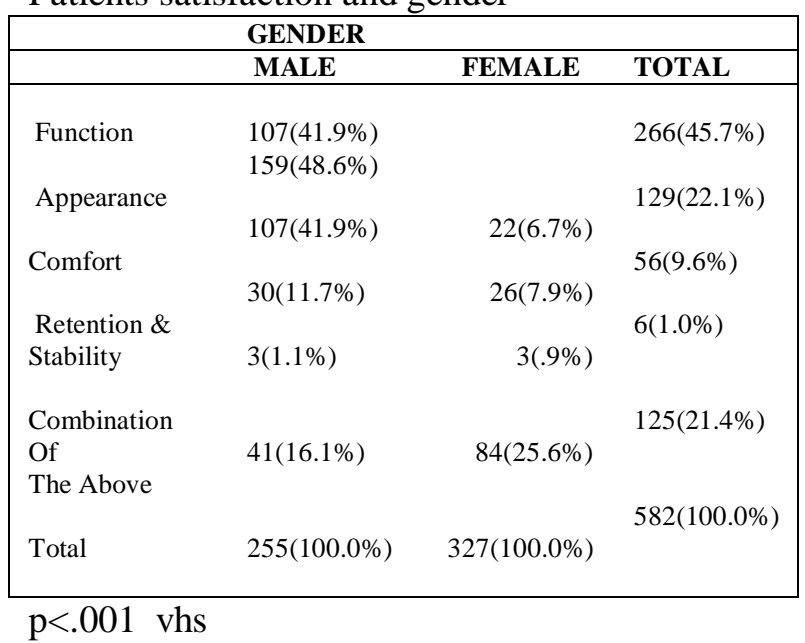

The distribution of subjects according to Patients satisfaction and education is given in Table 4. Satisfaction with the functioning of the prosthesis was seen more in illiterates and least in graduates. Patient satisfaction was found to be significantly related to the educational levels.

Table 3 : Distribution according to Patients satisfaction and Age group

\begin{tabular}{|l|l|l|l|l|l|l|l|l|}
\hline & & & & $\begin{array}{l}\text { AGE } \\
\text { GROUP }\end{array}$ & & \\
\hline & $<20$ & $21-30$ & $31-40$ & $41-50$ & $51-60$ & $61-70$ & $>=70$ & Total \\
\hline Function & $14(32.6 \%)$ & $47(29.9 \%)$ & $54(42.5 \%)$ & $57(55.9 \%)$ & $52(57.7 \%)$ & $34(65.4 \%)$ & $8(66.7 \%)$ & $266(45.7 \%)$ \\
Appearance & $16(37.2 \%)$ & $42(26.7 \%)$ & $29(22.8 \%)$ & $13(12.8 \%)$ & $15(16.7 \%)$ & $10(19.2 \%)$ & $4(33.3 \%)$ & $129(22.0 \%)$ \\
$\begin{array}{l}\text { Retention \& } \\
\text { Stability }\end{array}$ & $0(.0 \%)$ & $0(.0 \%)$ & $1(.8 \%)$ & $2(2.0 \%)$ & $1(1.1 \%)$ & $2(3.8 \%)$ & $0(.0 \%)$ & $6(1.1 \%)$ \\
$\begin{array}{l}\text { CombinatIon } \\
\text { of the }\end{array}$ & $12(27.9 \%)$ & $43(27.5 \%)$ & $34(26.7 \%)$ & $19(18.6 \%)$ & $13(14.5 \%)$ & $4(8.7 \%)$ & $0(.0 \%)$ & $125(21.4 \%)$ \\
\begin{tabular}{l} 
Total \\
\hline
\end{tabular} & $43(100 \%)$ & $156(100.0 \%)$ & $127(100.0 \%)$ & $102(100.0 \%)$ & $90(100 \%)$ & $52(100.0 \%)$ & $12(100.0 \%)$ & $582(100 \%)$ \\
\hline
\end{tabular}

$\mathrm{p}<.001$ vhs

\section{DISCUSSION}

Not much research has been conducted among the rural population with regard to satisfaction with the removable prosthesis. In contrast to our study which was community based, most of the studies have been conducted in hospital settings. 
Table 4: Patients satisfaction and education

\begin{tabular}{|c|c|c|c|c|c|}
\hline & EDUCATIO & & & & \\
\hline & Illiterate & Primary & High school & Graduates & Total \\
\hline Function & $12(52.2 \%)$ & $136(48.7 \%)$ & $105(42.3 \%)$ & $13(40.6 \%)$ & $266(45.7 \%)$ \\
\hline Appearance & $3(13.0 \%)$ & $59(21.1 \%)$ & $62(25.0 \%)$ & $5(15.6 \%)$ & $129(22.2 \%)$ \\
\hline Comfort & $4(17.4 \%)$ & $25(9.0 \%)$ & $22(8.9 \%)$ & $5(15.6 \%)$ & $56(9.6 \%)$ \\
\hline Retention \& Stability & $0(.0 \%)$ & $3(1.1 \%)$ & $3(1.2 \%)$ & $0(.0 \%)$ & $6(1.0 \%)$ \\
\hline Combination of the above & $4(17.4 \%)$ & $56(20.1 \%)$ & $56(22.6 \%)$ & $9(28.2 \%)$ & $125(21.4 \%)$ \\
\hline Total & $23(100.0 \%)$ & $279(100.0 \%)$ & $248(100.0 \%)$ & $32(100 \%)$ & $582(100.0 \%)$ \\
\hline
\end{tabular}

In this study 582 subjects [255 male (43.6\%) and 327 female (56.4\%)] formed the study population which was higher when compared to study by Abdel et al (2) done in a hospital on 66 patients. Another study by Ducia $\mathrm{CC}$ et al (1) on functional evaluation of oral rehabilitation with removable partial dentures after five years, examined 129 subjects. A study by Dubravka KZ et al (3) on 165 subjects was done in a dental school and in a geriatric institution.

Therefore, this study aims to find the effectiveness of therapy by evaluating patient satisfaction with function, appearance, retention and stability and comfort of removable prosthesis in a rural population.

There was a significant difference between men and women in the level of satisfaction with their partial dentures in function, appearance and comfort, whereas a study by Abdel Salam et al (2) shows no significant differences between men and women in the level of satisfaction with their partial dentures in function, appearance and comfort and between patients of different age groups.
Women were more satisfied with the function of the prosthesis than men which is in agreement with the study by Zlataric DK et al (4), Dubravka KZ et al (3) and Alma KC et al (5) .This could be mainly because of the food habits. Men give importance to the efficiency of the prosthesis while chewing. A study by also shows that women wearing partial dentures were more satisfied than men with mastication.

Significant difference was found between patients of different age groups with regard to function. $45.7 \%$ of the subjects were satisfied with the functioning of the prosthesis, when evaluated for ability to speak, chew, consume water, blow, and swallow. The level of satisfaction was more in the 61 and above age group. Whereas a study by Abdel et al (2) assessed each individual function and had the following findings for speech, eating and taste effect with dentures: fifty (83.3\%), forty-eight $(80.0 \%)$, forty-four $(73.3 \%)$ respectively were strongly satisfied. In our study the dissatisfaction was seen mainly in the 21to30year age group. Non acceptance towards removable prosthesis in this age group could be due to denture flange occupying the palate and lingual sulcus which 


\section{DOI: $10.16899 /$ ctd. 58786}

interferes with the tongue movements taste and speech. According to Frank et al (6) patients younger than 60 years were more dissatisfied than others.

$22 \%$ were satisfied with the appearance of the prosthesis. Subjects $<20$ year age group were most satisfied. According to the study by Abdel et al (2) $48.3 \%$ of patients were strongly satisfied with the appearance.

The dissatisfaction was seen mainly among those 41 to 50years of age, the probable reason being, that subjects of this age group want to retain their youthful looks, as they are growing old so psychologically they want to look better. Wakabayashi et al (7) found that the age has influence on satisfaction, because younger patients were more dissatisfied with aesthetics of denture. They also found significant correlation between patient attitudes towards ageing and patient acceptance of new denture.

When comfort with chewing, laughing, swallowing, inserting or removing the denture was evaluated, $9.6 \%$ were comfortable with the prosthesis. The dissatisfaction was seen mainly among those above 70 years of age, the probable reason could be the age, as patient's general adaptive capacity tends to deteriorate with increasing age, ridge resorption and poor general health. $1 \%$ of subjects were satisfied with the retention and stability of the prosthesis. The dissatisfaction was seen mainly among those above 70years of age, 21-30 and less than 20years of age, the probable reason being ridge resorption in elderly and unrealistic expectations in younger age group.

When education was considered Graduates were least satisfied with the removable prosthesis which could be due to the unrealistic expectation they have about the functional and esthetic values of dentures .The awareness of fixed prosthesis and implants may also lead to dissatisfaction with the removable prosthesis in the highly educated group. Economic status could also be another reason. This finding is in agreement with the study done by Dubravka KZ et al (3) and Zlataric DK et al
(4) wherein highly educated patients were less satisfied with the aesthetic appearance of their partial dentures. In this study Illiterates were least satisfied with the appearance, which may be due to awareness and exposure to the media. Men were more satisfied with the appearance of the prosthesis than women because women are more conscious of their looks and they pay more attention to appearance. In our study high school educated had least comfort. Illiterates and graduates were dissatisfied with retention and stability of the dentures.

\section{CONCLUSION}

Several factors influence the success of prosthesis. Only $1 \%$ of the subjects were found to be satisfied with the retention and stability, so no matter how skilled a professional may be, the acceptance of the prosthesis plays a pivotal role in the success of the prosthesis. Besides rehabilitating, the professional must also motivate the subjects and create positive attitude towards prosthetic acceptance.

Acknowledgement: The authors have acknowledged the assistance provided by $\mathrm{Dr}$ Rekha P Shenoy. The project was self-funded.

\section{REFERENCES}

1. Ducia CC, Simone MB, Eduardo DLF, Elken GR, Cassiano KR, Rosemary SAS . Functional evaluation of oral rehabilitation with removable partial dentures after five years. J Appl Oral Sci 2006; 14 (2):111-16.

2. Abdel Salam MA, Aamir MB, Abdul QD .Removable Partial Dentures: Patient satisfaction with associated demographic and biomechanical factors. Pakistan Oral \& Dental Journal 2012; 32(3):564-68.

3. Dubravka KZ, Celebic A, Melita VP,Vjekoslav J, Robert C, Irina FZ, Iva A. Patients' Satisfaction with Partial Denture Therapy. Acta Stomatol Croat2000;34(4): 373-78.

4. Zlataric DK, Celebic A, Valentic PM, Celic R, Filipovic ZI, Baucic M. The satisfaction with the removable partial denture therapy in the Croatian adult population. Coll Antropol. 2000; 24(2):485-94.

5. Alma KC, Amela D, Muhamed A, Adela D. Assessment of Patient's Satisfaction with the Partial Removable Denture .Pesq Bras Odontoped Clin Integr, Joao Pessoa, ISSN - 1519-0501, 2011; 11(2):171-75.

6. Frank RP, Milgrom P, Leroux BG, and Hawkins NR. Treatment outcomes with mandibular removable partial dentures: A population-based study of patient satisfaction. J Prosthet Dent 1998; 80:36-45.

7. Wakabayashi N, Yatabe M, Ai M, Sato M, Nakamura K. The influence of some demographic and clinical variables on psychosomatic traits of patients requesting replacement removable partial dentures. J Oral Rehabilitation 2002; 25(7):507-12. 